\title{
Jornalismo cultural, uma panóptica do nosso tempo
}

\author{
Cultural journalism, a panoptic of our time \\ Luís Carmelo - Universidade Autónoma de Lisboa \\ NIP-C@M \\ CECS-UMinho \\ Icarmelo@autonoma.pt \\ https://doi.org/10.26619/978-989-9002-14-2.6
}

\begin{tabular}{|c|c|c|}
\hline Recebido / Received & Aceite / Accepted & Publicado / Published \\
28.05 .2020 & 04.06 .2020 & 15.01 .2021 \\
\hline
\end{tabular}

Como citar este capítulo / How to quote this chapter:

Carmelo, L. (2021). "Jornalismo cultural, uma panóptica do nosso tempo". In Lourenço, J. \& Lopes, Comunicação, Cultura e Jornalismo CulturalLisboa: NIP-C@M \& UAL,.(pp. 111-137), disponível em https://repositorio.ual.pt/ handle/11144/4754 DOI https://doi.org/10.26619/978-989-9002-14-2.6 


\section{Resumo}

A integração contemporânea de diversos níveis de cultura parece reatar uma harmonia que pré-existia no alvor da modernidade. No entanto, distante da protecção da graça divina ou dos faróis ideológicos, a cultura é, hoje em dia, um campo em construção que se interroga e cuja codificação já está muito distante das noções iluministas. No seu conjunto, diríamos estar, ao mesmo tempo, perante uma indústria e uma panóptica que se autoanalisa em tempo real. É focado nesta multiplicidade que o jornalismo cultural emergiu, nas últimas décadas, enquanto manifestação própria de um mundo horizontal, em rede, plural, processual e que se manifesta através de várias camadas, sem que para elas exista um diagnóstico final.

\section{Abstract}

The contemporary integration of various levels of culture seems to reave a harmony that pre-existed in the dawn of modernity. However, far from the protection of divine grace or ideological beacons, culture is today a field under construction that is being questioned and whose codification is already far removed from the Enlightenment notions. On the whole, we would say, at the same time, that we are faced with an industry and a panopticon that analyses itself in real time. It is focused on this multiplicity that cultural journalism has emerged in recent decades as its own manifestation of a horizontal world, in network, plural, procedural and manifested through several layers, without a final diagnosis. 


\section{A harmonia perdida}

O jornalismo cultural é filho da transição de um mundo vertical, regido por grandes códigos totalizantes, para um mundo horizontal, baseado no estatuir de um espaço público e de uma sociedade aberta.

A abordagem de U. Eco em 'Apocalípticos e Integrados' (1964) permitiu enquadrar esta metamorfose que se foi tornando abrupta no último terço do século XX. A obra clarificou uma separação que a realidade estava então gradativamente a dissuadir. Por um lado, a crescente cultura de massas era vista como um esteio popular que se oporia à tradição da alta cultura; por outro lado, a cultura de massas era entendida como um alargamento normal, susceptível de ser fruída por toda a comunidade. Este segundo termo vingou claramente e acabaria por encontrar nas tecnologias um adjuvante que levou, na mesma época, autores como M. McLuhan ou $\mathrm{H}$. Innis a identificarem as morfologias dos meios de comunicação com um renovado poder cultural e informativo capaz de influenciar drasticamente a sociedade.

Em 1986, A. Mota, situava no pós-1974 o surgimento do jornalismo cultural em Portugal: "Surgiu o chamado jornalismo cultural em ligação estreita com o desenvolvimento da indústria cultural, nestes últimos doze anos. Encontravam mercado crescente os seus produtos e os mass media, arregaçavam as mangas, apropriaram-se dessa nova fatia de espaço público. A expansão da instituição escolar, concretizada no saldo educati- 
vo, e o ascenso das perspectivas de promoção social em mais amplas camadas populacionais ampliaram os auditórios em torno da televisão e da rádio, dos espetáculos (de cinema, teatro, música, etc.) e das exposições, dos variados festivais, congressos e encontros, da edição e comércio de livros, discos, vídeos etc" (1986, p. 89). Inferir-se-á, portanto, que o novo jornalismo cultural passou também a ser encarado como uma indústria cultural.

De algum modo, pode dizer-se que a erupção da cultura de massas que se inicia de modo vibrante nos anos sessenta do século XX recuperou uma unidade perdida que tinha a sua origem nos inícios da modernidade. No seu clássico Universos da Crítica (1982), E. Prado Coelho sublinhou a importância do processo de autonomização do mundo cultural nos alvores do romantismo: "Processo ambíguo: ao instituírem o seu espaço próprio, os artistas e intelectuais separam-se do conjunto da sociedade e da coerência cultural que a define. Anteriormente havia uma cultura popular consideravelmente viva e uma relação de harmonia e correspondência entre os artistas e esta cultura. Com a modernidade, tal harmonia entra em crise e acaba por se desfazer" (1982: 186).

Foi ainda no âmago dessa nostálgica "harmonia" que surgiram as primeiras gazetas, começando inicialmente por se alimentarem "essencialmente de notícias, embora no modelo inglês" (...) "o artigo de cariz opinativo tenha tido uma importância relevante, tendência que, de resto, alastrou à imprensa de todo o continente..." (J. P. Sousa, s/d: 83). Este legado ligado à opinião e ao 
"juízo" (aspecto que Kant aprofundaria no final do seu período crítico na década de oitenta do séc. XVIII) cedo encontrou espaço na nova percepção da "cultura". É em 1665 que, em França, surge o primeiro jornal cultural: o 'Journal des Savants' (1665): "Tratava-se de um semanário de doze páginas e com um formato um pouco maior do que o de La Gazette, que difundia resenhas e comentários de livros bem como artigos sobre temas científicos, históricos e artísticos. É um dos melhores exemplos de como o jornalismo emergente procurava já não apenas uma segmentação dos públicos mas também corresponder ao novo espírito iluminista da llustração". (ibidem: 89). No outro lado do canal, publicações como 'The Transactions of the Royal Society of London' de 1665 ou 'The Spectator' de 1711 passaram igualmente a dedicar textos a obras de teor literário e artístico.

Mas foi nas Luzes, sobretudo na segunda metade de setecentos, que o legado dos cafés, dos botequins e dos clubes surgiu e com eles um espaço de debate racional em torno de temas políticos, sociais, económicos, científicos e literários, abrindo as portas ao que viria a designar-se por espaço público moderno. Este vasto campo de recepção e de interpelação iluminista visava o sentido dos projectos modernos emergentes, baseados na dupla ciência - arte. A ciência e o mundo experimental dependendo dos factos e da realidade, a criatividade artística e estética criando factos e gerando realidade. Este entrosar de natureza essencialmente inventiva sucedia às teo-semioses que entendiam o universo como um dado adquirido e (sempre e já) por si divinamente explicado. Dois modos de significar a vida que se cruzam lenta- 
mente e que espelham o modo como o homem se vai impondo como sujeito criador ao longo da modernidade.

Contudo, as primeiras teorizações da arte e da estética e posteriores aprofundamentos (associados a aspectos como a criação, a inspiração, a imaginação, etc.) mantiveram um vínculo profundo (por vezes invisível) com formas espirituais de significar o mundo. Para Baudelaire, a conquista do belo - o primeiro grande elemento da estética - continuava a situar-se na linha da ancestral "cultura da promessa" (2004: 34).

As origens do estético e do culto moderno da noção de criação remetem para uma herança mais antiga, segundo alguns autores recuam mesmo à tradição gnóstica, e encontram eco em noções algo metafísicas como a de "génio" de Kant. No século $\mathrm{XX}$, o domínio pragmático e as relações construtoras que acabariam por ligar o artista/autor ao mundo entraram em cena, sendo o conceito de "acto criativo" de Duchamp (1987) um dos entrepostos teóricos mais interessantes que se aproximam dos já referidos 'Integrados' de U. Eco, criando condições para as abordagens de múltipla focagem do que viria a designar-se por jornalismo cultural.

O jornalismo cultural herda diversos percursos críticos singularizados com origem no século XVIII. O conceito de crítica é, desde logo, um conceito filosófico iluminista que implica, não tanto questionar como se conhecem e significam objetos, mas antes perguntar se e como o conhecimento e a significação se tornam 
possíveis. Quem diz o conhecimento e a significação diz todos os objectos particulares criados pela subjectividade humana. Esta dimensão "transcendental" de auto-interrogação é a que, no concreto, emerge em setecentos em disciplinas particulares.

No caso das artes plásticas, por exemplo, é difícil dissociar a matriz da crítica de Diderot nos "Salões" que se iniciaram no Louvre no ano de 1725 e que, um quarto de século mais tarde, em 1751, tiveram um grande impulso no momento em que passaram ao regime de Bienal. Depois da revolução de 1789, o espaço foi aberto a não académicos e o impacto internacional foi imenso. $O$ primeiro dos Salões de Denis Diderot, sob forma epistolar (como se fosse uma carta dirigida a F. Grimm) data de Setembro de 1759. O género adoptado pelo autor é inovador e pressupõe um estilo breve, vivo e não exaustivo, tendo como horizonte a existência de novos media (as gazetas e outros veículos que circulavam já no ainda incipiente espaço público). Estes primeiríssimos textos críticos visam a obra e o artista e desenvolvem-se em jeito de comentário. A perspectiva é claramente intersubjectiva ao nível da interpretação, quer das mensagens artísticas, quer das implicações teóricas subjacentes. Os "Salões" aceleraram a criação de um público específico, difundindo tendências, propondo modalidades de gosto e novas formas de ajuizar, para além de terem promovido a autonomia e um dado recorte à linguagem da crítica.

A crítica do livro e da literatura é contemporâneo a este fenómeno. Não é por acaso que, na pobre tradição epistolar portu- 
guesa, se encontra por essa época o livro de um estrangeirado, Cavaleiro de Oliveira, justamente com o título 'Cartas Familiares, Históricas, Políticas e Críticas' (1742). Na Alemanha, umas décadas depois, a revista 'Athenaeum' (1798), que reuniu em torno de si os românticos de lena com destaque para os irmãos Schlegel, colocou em evidência a extrema necessidade da crítica, sinónimo de atribuição ao sujeito do seu poder ao mesmo tempo criador, construtor e visionário.

Relembremos que a ideia de sujeito autónomo é uma ideia francamente moderna e, tal como M. Foucault sublinhou em Les Mots et les choses (1966), corresponde ao verdadeiro aparecer do homem crítico e livre: "Quando a história natural se transforma em biologia, quando a análise das riquezas se volve em economia, quando sobretudo a reflexão sobre a linguagem se converte em filologia e se extingue o discurso clássico em que o ser e a representação encontravam o seu espaço comum, então, no movimento profundo de uma tal mutação arqueológica, surge o homem com a sua posição ambígua de objecto para um saber e de sujeito que conhece: soberano submetido, espectador olhado..." (1988: 351).

É nesta dimensão afirmativa e livre que se pode compreender a ligação entre a crescente produção narrativa e a crítica em finais de setecentos, numa altura em que se assiste ao alargamento de públicos da cultura, ao desenvolvimento da indústria e do comércio livreiro e, no limite, à formação de uma opinião pública. 


\section{As novas codificações da cultura}

O conceito de cultura, tal como hoje ainda maioritariamente o entendemos, provém igualmente do século XVIII. Segundo Johann Herder, na sua conhecida e inacabada obra Ideen zur philosophie der geschite del Menschheit (1784-1791), a cultura é o todo que o homem faz ${ }^{1}$. A súmula desse produto, material ou imaterial, implica a objectivação de sentidos de pertença, de formas de reconhecimento e de partilhas de conteúdo e de expressões. Outros termos de meados do século XVIII já se haviam aproximado do conceito de Herder, caso de "século" (Voltaire) ou de "civilização" (Jean-Baptiste de Mirabaud)².

Estes processos de objectivação, que abrangem o final de setecentos e o início do século seguinte, tendem a enfatizar um todo abstracto: a cultura. As obras particulares passam, segundo esta nova perspectiva, a ser a resultante de uma tradição co-

10 original da autoria de Herder, Ideen zur philosophie der geschite del Menschheit, redigido até ao livro XX entre 1784 e 1791, desenvolve a noção de cultura - "Kultur" - baseada no fazer humano. Destaque para três capítulos seminais da obra: em X.3, focando as origens asiáticas do ser humano ("Der Gang der Kultur und Geschichte gibt historische Beweise, daß das Menschengeschlecht in Asien entstanden sei"); em XV.3, desenvolvendo a inevitabilidade das mudanças (e salvaguardando um papel especial à justiça e à razão - "Das Menschengeschlecht ist bestimmt, mancherlei Stufen der Kultur in mancherlei Veranderungen zu durchgehen; auf Vernunft und Billigkeit aber ist der daurende Zustand seiner Wohlfahrt wesentlich und allein gegrundet") e, em XX.4, abordando especificamente o papel da razão na Europa ("Kultur der Vernunft in Europa"). A obra, inacabada, tinha na sua parte apenas projectual (o que viria a ser a Parte 5 /livro XXI) uma secção dedicada a Portugal e Espanha, com ênfase para as descobertas e para a unificação ibérica ("6. Spanien und Portugal: Die Vereinigung Spaniens. Die Entdeckungen").

2 Voltaire, (1984). O Século de Luís XIV. 2 vols. Lisboa: D. Quixote; Mirabaud, J. B. (1751). Première Partie. In Le Monde, son origine et son antiquité. [Em linha.] Alondres (B.R.) disponible en: http://gallica.bnf.fr/ark:/12148/bpt6k730918/f2.image [Consult. 22 Mai. 2020]. 
lectiva, de uma história espiritualizada e, em última análise, de uma hipostasia da nova noção de corpo social. A cultura ocupa e reata em moldes radicalmente diversos o campo da Graça de Deus e da teodiceia, preenchendo-o com ingredientes racionais (com destaque para a codificação lógica e institucional) e com outros de natureza abstracta, contingente ou evocativa, casos, por exemplo, da nação, dos factores climáticos ou do próprio Volksgeist.

A designação de cultura nem sempre significou este fazer narrativo que é, hoje em dia, no entanto, um ponto de partida funcional para a compreensão do sentido de comunidade, independentemente da validação, ou não, de certos componentes tradicionais de índole iluminista (caso da dominante territorial ou linguística). Não deixa de ser interessante empreendermos uma breve viagem a bordo da palavra "cultura" para compreender como, por vezes, os trajectos semânticos não deixam de ter impactos ao nível semiótico (ou seja, ao nível mais vasto da significação social).

Tal com foi desenvolvido por Klaus Bruhn Jensen (1995), a actual palavra "cultura" deriva do latim "colere" que, há dois milénios, significava "cultivar" e andava associada à ideia de "tratar da" terra e dos animais, num sentido relativamente neutro (curiosamente próximo do conceito heideggeriano de "Sorge"/(cura³).

3 Sobre o termo "cura", refira-se a correspondência com o original alemão besorgen (ocupar-se), a partir do étimo sorge (cuidar de), que estrutura a "pre-sença" (dasein) e Ihe confere "constituição ontológica". Por fim, convém aditar que os outros modos de ser do "impessoal", além da "medianidade", são o "espaçamento" (espécie de condição de dependência face aos outros) e o "nivelamento" (que resulta do que é perspectivado pela totalidade das "possibilidades de ser"). Heidegger, M. (1997). Ser e Tempo. 
Com o tempo, o termo - que deveria herdar e incorporar no seu espectro semântico uma tradição oral pós-neolítica - foi-se substancializando através de novos conteúdos. O tipo expressivo de raiz agrícola manter-se-ia, em regime de ratio facilis (novos conteúdos alimentando a mesma expressão verbal) até aos nossos dias, no momento em que profundas alterações passaram a afectar esta fecunda memória dos gestos e acenos que sempre ligaram o homem às actividades da terra (à agricultura e à pecuária, entre outras).

Um primeiro sentido de teor secular (Plutarco, Cícero, etc.) remeteu, por conotação, para a ideia de cultivo do 'espírito humano'. Este entendimento da riqueza subjectivista equivalia à 'alma cultivada' pelo fruto da sabedoria (o conhecimento pessoal de cariz retórico, poético, filosófico, jurídico, etc.) e correspondia metaforicamente aos movimentos do arado num prado, também ele invicto e por cultivar. Esta terá sido a primeira adequação semântica à palavra original "cultura", realizada a partir do étimo latino de natureza agrícola que havia de se projectar até aos nossos dias em significações como "desenvolvimento intelectual", "saber", "estudo", "esmero" e ainda "elegância". Um homem muito culto equivalia e equivale, nesta acepção, a um homem com muito saber. E, neste caso específico, a correspondência entre 'cuidar da' terra e 'cuidar do' espírito não deixa de ser realmente assinalável4.

Petrópolis: Vozes, Parte 1 e 2, pp. 178-180 e 313. Ed. orig. Sein und Zeit. Tubingen: Max Niemeyer Verlag, 1927.

4 "Deriving from the Latin colere, to cultivate, the term 'culture' was originally associated with cultivating the earth and its animals in a relatively neutral sense, but over time it acquired two distinctly normative senses, one religious, the other secular. The religious, for example, in St. Augustine, who derived the concept of culture animi, cultivation of 
Um segundo sentido da palavra cultura decorreu da teo-semiose de Santo Agostinho que transpôs o conceito de "culture animi" da cultura subjectivista para o paradigma divino. A nova formação semântica teve (e tem ainda) uma vida intensa e acabou por associar, também até aos nossos dias, o uso da "cultura" (que mantinha ainda um claro rasto agrícola) ao uso do "culto" religioso. A correspondência entre as várias séries de 'cuidar de' - tendo como metaforizados o arado e a terra - alarga-se, desta forma, da "terra por cultivar" e do "espírito por cultivar" ao "ser" espiritualmente 'por cultivar' (neste caso pelo Espírito Santo). A ideia de 'cuidar de' reata sempre o seu caminho, desdobrando-se a novos campos e significações como se fosse, ela mesma, a interpretação de um sentido de fundo da existência humana.

Um terceiro sentido surgiu, como vimos, no lluminismo, por via do alemão Johann Herder. A nova visão celebrada através do neologismo latino "Kultur" acabaria por actualizar, no interior da língua alemã, uma nova vocação para a palavra: "Partindo do cultivo agrícola, podemos designar por cultura a génese que abarca o todo da vida humana." Esta noção moderna de cultura assentava e assenta na objectivação da totalidade do produto humano realizado, independentemente dos seus autores subjectivos. Nesta perspectiva, a imaterialidade e a materialidade historicamente acumuladas por uma dada comunidade (língua,

the human spirit, from Plutarch and Cicero, and rearticulated this to mean the cultivation of God by the human spirit, suggesting the common blurring of 'culture' and 'cult'. The secular sense of culture was recovered during the Renaissance and revitalized by the new middle classes of the modern period. Aesthetic or rhetorical competences could serve, literally, as a sign of distinction in contrast to both the uncultured working class and the superficial sophistication of the aristocracy." Klaus, B. J. (1995). The Social Semiotics of Mass Comunication. London; New Delhi: Safe Publishing; Thousand Oaks, p. 5. 
terra, tradição, arte, objectos 'culturais', etc.) passam a ser encaradas como obra do homem, isto é, como os produtos e a substância da sua própria cultura.

O diluir da lógica da civilização, particularmente activa durante o século XIX e início de novecentos, e que, a partir do final da Primeira Guerra Mundial, começou rapidamente a perder o fio-de-prumo "progressista" da sua crença, acabou por realçar ainda mais o papel iluminista da cultura. Deste modo, a cultura acentuou a sua marca de singularidade ao invés do tópico universalista (violento e mirificamente perfectível) tão próprio da civilização e da datada noção de "império". Neste jogo de remissões, apesar da aventura semântica se revelar pouco linear, a cultura acabaria por desenhar a longevidade de um conceito baseado num fazer acumulado e que sobretudo implicou - e implica - reconhecimento, pertença e partilha. Saliente-se que todas estas acepções de cultura deverão ser revisitadas como construções encenadas e não como produtos que, de uma forma dir-se-ia natural, o homem teria produzido como as abelhas "produzem o seu mel".

Existe ainda um quarto sentido de cultura que está a ser desenvolvido na contemporaneidade e que escapa, pela primeira vez, à referência memorial de matriz agrícola. Segundo A. McHoul, autor de Semiotic Investigations - Towards an Effective Semiotics (1996), ao contrário da visão moderna, o mundo passa a ser encarado como um volume policentrado, livre de estruturas fixas e sem clara base territorial. A culturização global dos 
hábitos passa assim a estar ligada às conectividades da rede e a novos tipos de partilha e de comunidades que o autor designa por "being-in-common". Este designado "estar em comum" global está fortemente ligado à instantaneidade dos gestos e à transparência da rede, na medida em que estes se convertem na substância de partilha e não apenas no instrumento que a possibilita.

A noção de "being-in-common", desenvolvida por A. McHoul, corresponde à disseminação territorial e interactiva da cultura e ainda à visão de comunidades

"that assemble (physically or by other means) for relatively common (including dissensual) semiotic activities. A comunity may be a traditional grouping such as a particular group of religious practitioners who meet regularly for common worship. But it may also be a looser group connected by relatively tenuous affinities, such as the "Trekkers" - fans of television and movie series [...] A community, then, is whoever (collectively) copes - methodically - together with what happens, which may conform to what we think are collective expectations." (1996: 127).

Nesta concepção, os membros da comunidade são sobretudo considerados como "course of activity recognizable for its directionality", assente num princípio de afinidade e cooperação, independentemente dos agentes subjectivos que protagonizam a actividade e dos locais onde se encontrem. Os participantes 
nas redes sociais ou na bolsa, os sem-abrigo, os clientes de hipermercado ou os consumidores de séries, apostas ou de reality shows e muitos outros agentes de outras reduplicações globais convertidas em fluxo de acção integram estas comunidades transterritoriais, partilhando sentidos, afinidades e múltiplas convergências. Factores que no início da modernidade eram vitais para a definição da noção de cultura, tais como as línguas naturais, o território e, de algum modo, a própria tradição, surgem aqui completamente reconfiguradas.

Esta proposta de A. McHoul implica, ao nível da auto-imagem da cultura, um corte com o seu legado neolítico original. Este corte tem como consequência uma ruptura significativa. É no espaço desse corte que estamos hoje em dia a viver, de algum modo apeados do que parecia ter sido, ao longo de séculos, e como antes se referiu, a interpretação de um sentido de fundo da existência humana. A aventura da cultura continua, no entanto, a existir como uma experiência em que as comunidades interrogam as formas, por vezes nada analógicas, com que se vêem e revêem ao espelho.

Em última análise, a noção de "being-in-common", desenvolvida por A. McHoul, corresponde à disseminação territorial e interactiva da cultura e não mais ao seu foco estritamente local. Há três décadas e meia, o JL publicou um texto de M. Kundera sobre a Europa que hoje parece profético a este respeito. Leiamos o seu momento fulcral: "A Europa não se apercebeu do desaparecimento do seu grande foco cultural, porque, para a Europa, a sua 
unidade já não simboliza a sua unidade cultural. Em que bases assenta então a unidade da Europa? Na Idade Média assentava numa religião comum. Nos tempos modernos, numa altura em que o Deus medieval se transformou em Deus absconditus, a religião cedeu o seu lugar à cultura, que passou a significar a concretização dos valores mais elevados" (...) "Da mesma forma que, em tempos passados, Deus cedeu o seu lugar à cultura, é agora a vez da cultura ceder o seu lugar. Mas a quê e a quem?" (1985: 22).

O sentido de interrogação acaba, hoje em dia, por se constituir, ele mesmo, como um cerne do fazer cultural e, portanto, do próprio agir do que se designa por jornalismo cultural. Isso significa também que o seu âmbito se abriu muito para a além daquilo que a tradição da alta cultura situava apenas no domínio da arte e da literatura. Deste modo, muitas outras tradições são hoje chamadas a jogo, tais como o design, a alimentação, os hábitos sociais, a moda, a pop, os fluxos da rede, ou seja, o lifestyle na sua generalidade corpórea ou virtual. No seu conjunto, diríamos estar, ao mesmo tempo, perante uma indústria e uma panóptica que se auto-analisa em tempo real, num desafio em que o jornalismo cultural se tornou num dos protagonistas essenciais.

\section{Novas vias: os patrimónios e as mobilidades do quotidiano}

Na frente desta panóptica de heranças tão diversificadas que é o jornalismo cultural pululam as mais diversas manifestações. Para além da tematização clássica em torno dos livros, da mú- 
sica, do cinema e das artes (entrelaçadas já com o design, a ciberficção e as mais diversas movimentações de arte efémera), o foco recai, cada vez mais, em domínios tangíveis do quotidiano (moda, manobras da corporalidade radical, práticas gourmet, etc.) e também intangíveis com natural destaque para os mais diversos cultos do património.

Curiosamente, do lado dos autores e da criação contemporânea, verifica-se a simétrica tendência de a oferta se descentrar igualmente num leque amplo de construções. Podemos dar o exemplo de Afonso Cruz (1971) que soma à narrativa ficcional, o discurso da viagem, o grafismo, a ilustração, o design, a fabricação de cerveja e ainda um halo performativo e musical. Podemos dar o exemplo de Patrícia Portela (1974) que ao romance junta o teatro, a performance, as artes plásticas e a instalação multimédia. Podemos dar ainda o exemplo de Gonçalo M. Tavares (1970) que, para além da fragmentação dos géneros clássicos dentro da área propriamente literária, desdobra a actividade ao nível da fotografia, da arquitectura, do teatro, da paródia à tradição mitológica e sobretudo da corporalidade (Atlas do Corpo, obra publicada em 2013, é, porventura, o maior indício dessa tendência).

Esta simetria em movimento ilustra bem o facto de a metáfora da panóptica se desterritorializar entre as dimensões do fazer e da crítica cultural, como também se desterritorializa entre o mundo on e offline. Uma e outra dessas dimensões (o fazer criativo e a leitura desse fazer) interpenetram-se sem que o foco se centre e sem que a descentragem se deixe demarcar. A alegoria da rede impõe assim os seus processos e traça morfologias a 
que o jornalismo cultural da actualidade não é, de modo nenhum, alheio.

Esta mobilidade nos processos é paralela ao caudal de informação online que acaba por se traduzir numa espécie de excesso de eficácia que se contrapõe à ideia clássica de individualidade, de subjectividade e de corpo. O que apreendemos, hoje em dia, é sempre um excerto, uma panóplia de fragmentos, um zapping desse infindo mundo de bits. Daí que as subjectividades assumam hoje características de um corpo e de uma subjectividade protéticos ou cyborguizados; neles, a realidade é uma plasticina sempre em movimento criada pela re-arrumação permanente de bits. A maior angústia dos internautas - heterónimo que todos hoje incorporamos - decorre do desfasamento entre aquilo que se decifra (como se fosse um instante ou um simples corte) e o fluxo sem fim a que acede em cada momento. É nesse desfasamento que a virtualização da individualidade age e reage aos próprios contextos que vai criando.

Esta mobilidade dos processos é paralela também à mobilidade física dos agentes e dos públicos. Cada vez mais o planeta está em viagem (física e territorial) e este dado é francamente permeável aos esquemas editoriais do jornalismo cultural. De facto, as mobilidades contemporâneas colocaram em cena uma nova rede de peregrinos que percorrem o organigrama dos bens naturais e culturais elevados, há poucas décadas, ao que passou a designar-se por "Património Mundial". Fazem-no do mesmo modo que atravessam a topografia das instâncias museológicas ou dos parques naturais (muitas vezes movidos por utopias am- 
bientais). Existe naturalmente um intuito lúdico, um certo devir utópico e, ao mesmo tempo, um agir em estado de fluxo nestas mobilidades. Mas o domínio patrimonial estatuído é aquele que mais está no centro dos novos turismos culturais, devido, muito provavelmente, à "universalidade" que foi tão explicitamente referida na Convenção da Unesco de 1972: "O que faz com que o conceito de património mundial seja excepcional é sua aplicação universal." 5 .

5 Os critérios de selecção que permitem a um dado sítio, "bem cultural" ou tradição ser ou não integrado na "Lista do Património Mundial" têm em conta um conjunto de condições alternativas, entre as quais se destaca a primeira: "i) representar uma obra-prima do génio criativo humano." A imagem inicial associa a ideia de "génio" aos atributos "criativo" e "humano", fazendo-os depender do dado mais substantivo que é enunciado: a "obra-prima". A auto-imagem do homem, enquanto criador superlativo e ímpar, desenvolve, de forma explícita, a ideia de uma redenção que é consubstanciada através das suas próprias obras transpostas do passado para o presente. $\mathrm{O}$ segundo critério é assim enunciado: [O]u [...] ii) ser a manifestação de um intercâmbio considerável de valores humanos durante um determinado período ou em uma área cultural específica, no desenvolvimento da arquitectura, das artes monumentais, de planeamento urbano ou de paisagismo". Esta segunda condição propõe, num espaço e num tempo delimitados, o domínio construtivo onde se tenha projectado uma comunicação de "valores humanos" adjectivado como "considerável". O homo faber está aqui verdadeiramente no centro, complementando o dom inato - o "génio" - que antes havia sido referido. As restantes quatro condições relevam testemunhos e exemplos que são, em todos os casos, adjectivados como "excepcionais". O atributo "excepcional" já aparecera no terceiro período da definição de Património no site da unesco ("O que faz com que o conceito de Património Mundial seja excepcional é sua aplicação universal"), o que remete para uma intencionalidade que sublinha a dimensão ímpar que é atribuível ao fazer do homem. Se a noção de cultura é uma noção que se objectiva como uma realidade de facto (algo que se constata na distância com que pode ser analisada), já a noção de património, pela maneira como é enunciada, se coloca num patamar acima, na medida em que não se exime à esfera judicativa. Leiamos, em conjunto, os terceiros, quartos e quintos critérios de selecção - sempre alternativos - que permitem aos "bens culturais" serem ou não integrados na "Lista do Património Mundial": (iii) aportar um testemunho único ou excepcional de uma tradição cultural ou de uma civilização ainda viva ou que tenha desaparecido, ou (iv) ser um exemplo excepcional de um tipo de edifício ou de conjunto arquitectónico ou tecnológico, ou de paisagem que ilustre uma ou várias etapas significativas da história da humanidade, ou (v) constituir um exemplo excepcional de habitat ou estabelecimento humano tradicional ou do uso da terra, que seja representativo de uma cultura ou de culturas, especialmente as que tenham se tornado vulneráveis por efeitos de mudanças irreversíveis. O testemunho e os exemplos remetem para o carácter único de legados materiais ou imateriais, explicitando a pluralidade e a fragilidade, motivada por contingências históricas. A valorização é aqui extensiva ao que se apresenta como um vestígio raro, embora sempre em correlação com a ideia de uma narrativa criada pelo homem, enquanto 
Nos critérios seguidos pela Unesco para a atribuição de património mundial, sobretudo quando estão em causa os chama dos "bens culturais", a terminologia usada, o tipo de alegações enunciadas e o que nelas subjaz ao nível do "genial" e do "excepcional" reflectem um processo de quase sacralização (F). Esse processo será, na prática, tão mais contundente quanto a desordem urbana e a destruição dos recursos naturais impliquem uma consciência que alia a necessidade de resistência (ecológica) à necessidade de novas referências - neste caso de cariz patrimonial - que consigam tornar-se ostensivas no mundo comunicacional em que vivemos (tão dominado pela redundância da comunicação pela comunicação).

sujeito central que é pautado pela sua sempre possível excepcionalidade. 0 derradeiro critério coloca o acento tónico em obras de arte, ideias ou tradições que perdurem até ao presente e que se revelem como marcos da espécie humana (a designação utilizada é mais generalista: de "significado universal excepcional"). Leiamos toda a passagem: "[o]u [...] vi) estar associados directamente ou tangivelmente a acontecimentos ou tradições vivas, com ideias ou crenças, ou com obras artísticas ou literárias de significado universal excepcional (o Comité considera que este critério não deve justificar a inscrição na Lista, salvo em circunstâncias excepcionais e na aplicação conjunta com outros critérios culturais ou naturais)". O parêntesis hierarquiza os critérios, atribuindo à sequência que termina no quinto critério um cariz primacial. Os critérios adoptados para os "bens naturais" reatam também, em todos os casos, o atributo "excepcional" e enfatizam dimensões diversas, como a histórica, a ecológica, a biológica e a estética (neste caso, recorrendo a uma terminologia dos inícios da disciplina estética: "[B]eleza natural e uma importância estética excepcionais"). Na lista, a dimensão humana não é explicitamente referida, a não ser quando o "valor universal excepcional do ponto de vista da ciência" se situa no texto: (i) serem exemplos excepcionais representativos dos diferentes períodos da história da Terra, incluindo o registo da evolução, dos processos geológicos significativos em curso, do desenvolvimento das formas terrestres ou de elementos geomórficos e fisiográficos significativos, ou (ii) ser exemplos excepcionais que representem processos ecológicos e biológicos significativos para a evolução e o desenvolvimento de ecossistemas terrestres, costeiros, marítimos e de água doce e de comunidades de plantas e animais, ou (iii) conter fenómenos naturais extraordinários ou áreas de uma beleza natural e uma importância estética excepcionais, ou (iv) conter os habitats naturais mais importantes e mais representativos para a conservação in situ da diversidade biológica, incluindo aqueles que abrigam espécies ameaçadas que possuam um valor universal excepcional do ponto de vista da ciência ou da conservação. 
Esta perspectiva é também um diagnóstico que nos afirma que os vazios deixados pelo definhar das codificações axiais (escatológicas ou ideológicas), quer no futuro, quer no passado, encontraram exaltações e paradigmas novos que os foram adequadamente preenchendo. Os fluxos de incidência tecnológica foram preenchendo o esvaziamento do futuro, enquanto o culto do património - num sentido lato simultaneamente natural e cultural - foi, pelo seu lado, preenchendo o esvaziamento do passado.

Uma nova transcendência, embora não declarada, parece emergir nos limites do presente em que passámos a viver, colocando a montante (o património) e a jusante (a tecnologia) cenários simulados de conforto que acabam por nos dar uma sensação, ao mesmo tempo, retrospectiva e projectiva. Como se a cultura em que vivemos necessitasse de contextos para respirar e de centros para se referenciar. Quando o mundo em que vivemos é, afinal, cada vez mais acentrado e cada vez mais descontextualizado. É neste jogo de simulacros e simulações permanentes que o jornalismo cultural é obrigado a mover-se e, portanto, a desdobrar-se no mundo de hoje.

\section{Breve conclusão}

Muito antes da abertura pós-moderna que data do último quarto do século $X^{6}$, já o impacto das teorias da linguagem que

6 Para P. Sloterdijk, o prefixo "pós" reflecte uma inflexão, ou seja, uma passagem abrupta de um tempo que visava um clímax, um cume ou um ponto-ómega, para um outro tempo de puro processo e, por isso, aberto a múltiplas vias. Em virtude desta cisão com um clímax augurado e, portanto, com o sentido teleológico da história, a falta de compromisso instalou-se no coração do presente. A codificação do tempo deixou de ser linear e passou a ser multipolar. Segundo o autor, ao contrário por exemplo de J.-F. Lyotard, não existem ecos substanciais, mas tão-só processuais, na designação 
foram substituindo a verdade (como critério central e vertical para significar o mundo) pela pluralidade de sentidos se havia começado a sentir (citar autores).

O ponto de partida encontra-se no segundo L. Wittgenstein (de Investigações Filosóficas, 19497) que defendeu que a análise da significação baseada nas condições de verdade se esgotara. No início da obra, o autor escreve: "cada palavra tem uma denotação". Mas depois pergunta. "Mas qual é a denotação da palavra 'cinco'?" E o próprio responde: "Aqui não se falou disso, mas apenas de como a palavra 'cinco' é usada" (I.1;1995: 172/173). De seguida, o autor precisa e delimita um conceito importantíssimo da nova fase: chamarei "ao todo formado pela linguagem com as actividades com as quais ela está entrelaçada o 'jogo da linguagem'" (I.7;1995: 177).

$\mathrm{O}$ linguistic turn aberto pelo segundo L. Wittgenstein criou condições para novas propostas no campo pragmático. Nas críticas ao logicismo de B. Russell, P. Strawson já havia dito que uma proposição entendida como falsa nunca podia ser considerada nem verdadeira nem falsa, mas antes desprovida de sentido. Na sequência de P. Strawson, J. Austin definiu e aprofundou as condições pragmáticas da comunicação e acrescentou ao nível

\footnotetext{
"pós-modernidade". Sloterdijk, P. (2001). Ensaio sobre a Intoxicação Voluntária. Lisboa: Fenda; Lyotard, J. F. (1989). A Condição Pós-Moderna. Lisboa: Gradiva, Ed. orig. 1979.

70 Tratado Lógico-Filosófico foi enviado, em 1920, pelo autor a B. Russel e a F. Frege, mas só seria editado em 1921 (após um ano em que L. Wittgenstein teve uma experiência como jardineiro). A obra Investigações Filosóficas, que afasta o autor da sua primeira fase, foi escrita durante 16 anos e só ficou completa em 1949, precisamente dois anos antes da morte de L. Wittgenstein.
} 
da locução (o acontecimento que se traduz por algo que se diz e pelo modo como tal é levado a cabo), o da ilocução (o compromisso ou a promessa, como dirá Deleuze, que esse acontecimento consubstancia) e o da perlocução (os efeitos produzidos pelo acto de dizer sobre o alocutário e sobre o próprio locutor). Esta pequena revolução que sucede o linguistic turn, chamemos-lhe o pragmatic turn, põe decisivamente em jogo o agir e o dizer, a acção humana e o próprio agir da linguagem. A intenção e a capacidade de decisão que estão ligadas ao agenciamento humano e que se propõem atingir metas através da manipulação do sentido, ou seja da significação, constituem-se como entidades autónomas face às adequações da linguagem ao que ela mesma significa (ou possa significar). O sentido impunha-se assim definitivamente à verdade e o imenso leque de provas desse facto, sucedendo a este patamar teóricos, tornou-se quase redundante no tempo da rede e das redes sociais.

Esta abertura radical à horizontalidade e à pluralidade de regras e, de modo ampliado, à ausência de referências duradouras tem-se traduzido, no mundo ocidental, por um modelo de vida que tende amiúde a perder o norte e, portanto, a perpetuar a ideia de uma crise perene do sentido. Uma parte substancial da nossa vida social, política e mediática reflecte esta carência de bússola, assim como um profundo colapso ao nível do 'dever ser', facto que G. Lipovetsky, em Crépuscule du devoir (1992), prenunciou profeticamente há já quase três décadas.

De algum modo, estamos a respirar hoje em dia aquilo que J. Derrida caracterizou como "desconstrução", entendida não 
apenas como mais uma teoria (de aparência, aliás, delirante), mas como um modo genuíno de expressão humana a que o jornalismo cultural, nos primeiros anos deste século, se tem vindo a moldar. As definições correntes desta área dos media têm grande dificuldade em encontrar um campo inclusivo e definido que as tornasse coerentes. É como se a realidade fosse sempre mais complexa e vasta do que a linguagem que a desejaria compactar e (utopicamente) referenciar. Veja-se o caso desta tentativa D. Santos Silva (2015) em que é patente um deambular dos mais variados esteios que se entrecruzarão no albergue do jornalismo cultural:

“...o jornalismo cultural é igualmente um conceito complexo, multidimensional e em evolução. Como resultado das escolhas editoriais, pode-se focar em manifestações artísticas, o processo da cultura, assuntos culturais e antropológicos, infraestruturas e bens culturais, lifestyle e qualidade de vida, entretenimento e lazer, criatividade e inovação. Portanto, o jornalismo cultural cobre potencialmente todas as dimensões da cultura: como objeto artístico e criativo, como um processo, como uma manifestação ou modo de vida da sociedade, como um bem tangível ou intangível, sempre ligado ao seu valor dentro da sociedade a cada momento, com diferentes géneros e tratamentos editoriais. O jornalismo cultural é em si uma prática cultural".

Sinal dos tempos. 


\section{Bibliografia}

AA.VV. (1972). Convenção para a protecção do património mundial, cultural e natural. [Em linha.]. Disponível em https://whc.unesco.org/ archive/convention-pt.pdf [Consult. 26 Mai. 2020].

Austin, J. (1971). Quand dire c'est faire. Paris: Seuil. Ed. orig. Philosophical Papers. Oxford: Oxford University Press, 1961.

Baudelaire, C. (2004). O Pintor da Vida Moderna. Trad. Teresa Cruz. Lisboa: Vega, Ed. orig. 1868/1870.

Carmelo, L. (1999). Anjos e Meteoros. Lisboa: Editorial Notícias.

Publicações Europa-América.

(2003). Semiótica: Uma Introdução. Mem Martins: (2003). Genealogias da Cultura. Lisboa: Arranha-Céus.

Coelho, E. P. (1982). Os Universos da Crítica. Lisboa: Edições 70.

Diderot, D. (1998). Essais sur la peinture: Salons de 1759, 1761, 1763. Textes établis et présentés par Gita May et Jacques Chouillet. Paris: Hermann, (Collection Savoir: Lettres).

Duchamp, M. (1997). O Acto Criativo de Duchamp. Trad. Rui Cascais Parada. Lisboa: Águaforte. Tit. orig. The Creative Act. Between intention and expression is the art coefficient. Art News. Vol. 57, no. 4 (Summer 1957).

Eco, U. (2015). Apocalípticos e Integrados. Trad. Helena Gubernatis. Lisboa: Relógio d’Água.

Foucault, M. (1988). As Palavras e as Coisas. Lisboa: Edições 70.

Heidegger, M. (1997). Ser e Tempo. Petrópolis: Vozes, Parte 1 e 2, pp. $178-180$ e 313. Ed. orig. Sein und Zeit. Tubingen: Max Niemeyer Verlag, 1927.

Herder, J. G. (1968). Reflections on the Philosophy of the History of Mankind. Ed. Frank E. Manuel, trad. T. O. Churchill. Chicago: University of Chicago Press.

Jensen, K. B. (1995). The Social Semiotics of Mass Comunication. London; New Delhi: Safe Publishing; Thousand Oaks. 
Kant, Immanuel. CEuvres Philosophiques III: Derniers Écrits. Paris: Gallimard, 1986.

(2017). Crítica da Faculdade do Juízo. Introd. António Marques, Trad. e notas António Marques e Valério Rohden. Lisboa: Imprensa Nacional Casa da Moeda.

Kundera, M. (1985). Europa Central: Um Continente Sequestrado. JL Jornal de Letras, Artes e Ideias. Lisboa : Projornal. № 164, p. 22.

Lipovetsky, G. (1992). O Crepúsculo do Dever. Lisboa: D. Quixote, 1994. Ed. orig. Le Crépuscule du devoir, l'éthique indolore des nouveaux temps démocratiques. Paris: NRF; Gallimard (Essays).

Lyotard, J. F. (1989). A Condição Pós-Moderna. Lisboa: Gradiva, Ed. orig. 1979.

Estampa.

(1990). O Inumano: Considerações sobre o Tempo. Lisboa:

McHoul, A. (1996). Semiotic Investigations: Towards an Effective Semiotics. Lincoln; London: University of Nebraska Press.

Mota, A. (1986). Jornalismo Cultural: o avatar e o voto. In Actas do II Encontro Afro-LusoBrasileiro. Jornalismo e Literatura. Lisboa: Vega, pp. 89-94.

Oliveira, F. X. (1855). Cartas Familiares, Históricas, Políticas e Críticas. Seguido de: Viagem à Ilha do Amor: escrita a philandro e dedicada ao Illustrissimo ao Illustrissimo Senhor Diogo de Mendoça Corte-Real. Por... Cavaleiro Prophesso da Ordem de N. S. Jesus Christo. Haya. M. DCC. XLIV. 3 Volumes, Lisboa.

Robert, S. M. (2015). O Jornalismo Cultural do Público na Era Digital. Faculdade de Ciências Sociais e Humanas, Lisboa, disponível em https://run.unl.pt/bitstream/10362/51213/1/Relatorio-estagio SofiaRobert.pdf [Consult. 26 Mai. 2020].

Santos Silva, D. (2015). Cultural Journalism in a Digital Environment New Models, Practices and Possibilities. Tese de Doutoramento - UT Austin | Portugal CoLab. Faculdade de Ciências Sociais e Humanas, Lisboa. 
Sloterdijk, P. (2001). Ensaio sobre a Intoxicação Voluntária. Lisboa: Fenda.

(2002). A Mobilização Infinita: para uma crítica da cinética política. Lisboa: Relógio d’Água, Ed. orig. 1989.

Sousa, J. P. (s.d.). Uma história breve do jornalismo no Ocidente, Universidade Fernando Pessoa/Centro de Investigação Media \& Jornalismo (s/d). Disponível em http://www.bocc.ubi.pt/pag/sousajorge-pedro-uma-historia-breve-do-jornalismo-no-ocidente.pdf [Consult. 26 Mai. 2020].

Tavares, G. M. (2013). Atlas do Corpo, Lisboa: Editorial Caminho.

Wittgenstein, L. (1995). Tratado Lógico-Filosófico. Investigações Filosóficas. Trad. e pref. M. S. Lourenço. Lisboa: Fundação Calouste Gulbenkian, Ed. orig. respectivamente 1921 e 1949. 